\title{
Effects of linagliptin on renal endothelial function in patients with type 2 diabetes: a randomised clinical trial
}

\author{
Christian Ott $^{1}$ - Iris Kistner ${ }^{1} \cdot$ Mirjam Keller $^{1} \cdot$ Stefanie Friedrich $^{1} \cdot$ Carsten Willam $^{1}$. \\ Peter Bramlage $^{2}$ • Roland E. Schmieder ${ }^{1}$
}

Received: 28 April 2016 / Accepted: 13 July 2016 /Published online: 1 September 2016

(C) Springer-Verlag Berlin Heidelberg 2016
Abstract
Aims/hypothesis Endothelial dysfunction predicts cardiovas- cular damage and renal involvement. Animal experiments and human studies indicate an increased nitric oxide (NO) activity and endothelial NO synthase (NOS) expression in the early stage of type 2 diabetes. The aim of the study was to assess the effect of linagliptin on the endothelial function of the renal vasculature.
Methods In this randomised, double-blind, parallel-group, investigator-initiated trial, 62 patients with type 2 diabetes were randomly assigned (by computer-generated random code) to receive linagliptin $5 \mathrm{mg}(n=30)$ or placebo $(n=32)$ for 4 weeks. The primary objective was to assess endothelial function of the renal vasculature, by constant-infusion input- clearance and urinary albumin/creatinine ratio (UACR), both before and after blockade of NOS with $N^{\mathrm{G}}$-monomethyl- L-arginine (L-NMMA).
Results Treatment with linagliptin for 4 weeks reduced fasting, postprandial blood glucose and $\mathrm{HbA}_{1 \mathrm{c}}$, although not significantly; no change occurred with placebo. Renal plasma flow (RPF) did not change after linagliptin or placebo. After 4 weeks the absolute change in RPF due to L-NMMA was smaller in the linagliptin group than in the placebo group $(-46.8 \pm 34 \mathrm{vs}-65.1 \pm 36 \mathrm{ml} / \mathrm{min}, p=0.045)$, indicating a low- er basal NO activity after treatment with linagliptin. Consistently, the response of UACR to L-NMMA increased
Roland E. Schmieder
roland.schmieder@uk-erlangen.de
Department of Nephrology and Hypertension,
Friedrich-Alexander-University Erlangen-Nürnberg (FAU),
University Hospital, Ulmenweg 18, 91054 Erlangen, Germany
2 Institute for Pharmacology and Preventive Medicine,
Mahlow, Germany
in the placebo group $(p=0.059)$ but not in the linagliptin group ( $p=0.276$ ), pointing to an upregulation of $\mathrm{NO}$ activity in the placebo group. No clinically meaningful safety con- cerns were evident.
Conclusions/interpretation Our data suggest that treatment with the dipeptidyl peptidase- 4 inhibitor linagliptin for 4 weeks prevented the impairment of renal endothelial func- tion due to hyperglycaemia in type 2 diabetes.
Trial registration: ClinicalTrials.gov NCT01835678
Funding: This study was funded by Boehringer Ingelheim.
Keywords DPP-4 inhibitor $\cdot$ Endothelial function $\cdot$ Nitric oxide $\cdot$ Renal $\cdot$ Type 2 diabetes

$\begin{array}{ll}\text { Abbreviations } \\ \text { DPP-4 } & \text { Dipeptidyl peptidase-4 } \\ \text { eGFR } & \text { Estimated GFR } \\ \text { eNOS } & \text { Endothelial nitric oxide synthase } \\ \text { ESRD } & \text { End-stage renal disease } \\ \text { GLP-1 } & \text { Glucagon-like peptide-1 } \\ \text { hs-CRP } & \text { High-sensitivity C-reactive protein } \\ \text { ICAM-1 } & \text { Intercellular adhesion molecule-1 } \\ \text { KIM-1 } & \text { Kidney injury molecule-1 } \\ \text { L-FABP } & \text { Liver-type fatty acid binding protein } \\ \text { L-NAME } & \text { L-N }^{\mathrm{G}} \text {-nitroarginine methyl-ester } \\ \text { L-NMMA } & N^{\mathrm{G}} \text {-monomethyl-L-arginine } \\ \text { MCP-1 } & \text { Monocyte chemoattractant protein-1 } \\ \text { NGAL } & \text { Neutrophil gelatinase-associated lipocalin } \\ \text { NO } & \text { Nitric oxide } \\ \text { PAH } & \text { Sodium } p \text {-aminohippurate } \\ \mathrm{P}_{\text {glom }} & \text { Intraglomerular pressure } \\ \mathrm{R}_{\mathrm{A}} & \text { Resistances of the afferent arteriole } \\ \mathrm{R}_{\mathrm{E}} & \text { Resistances of the efferent arteriole } \\ \text { RPF } & \text { Renal plasma flow }\end{array}$




\section{STZ Streptozotocin}

TIMP-2 Tissue inhibitor of metalloproteinase-2

UACR Urinary albumin to creatinine ratio

\section{Introduction}

Diabetic nephropathy is the cause of up to $50 \%$ of cases of end-stage renal disease (ESRD). Hence, an early intervention to prevent structural kidney damage is a desirable therapeutic goal. In the early stage of diabetic nephropathy endothelial dysfunction is a key pathogenetic mechanism as indicated by an increased leakage of albumin through the glomerular filtration barrier [1-3]. Endothelium-derived nitric oxide (NO) generated by endothelial NO synthase (eNOS) has been widely used as a marker of endothelial function in clinical research, and altered production and release of NO (i.e. reduced basal NO activity) can be directly assessed by systemic infusion of $N^{\mathrm{G}}$-monomethyl-L-arginine (L-NMMA) in humans [4, 5]. Increased basal NO activity is associated with glomerular hyperfiltration, the first stage of diabetic nephropathy $[6,7]$.

Dipeptidyl peptidase-4 (DPP-4) inhibitors are glucoselowering drugs that act by inhibiting the enzyme DPP-4, resulting in an increased and prolonged effect of glucagonlike peptide-1 (GLP-1) [8]. In a diabetic rat model it was shown that GLP-1 infusion nearly re-established normal vascular tone of aortic strips [9]. Moreover, in vitro studies revealed that DPP-4 is expressed in endothelial cells and that inhibition of DPP-4 reduced the microvascular tone through direct mediation of the NO system [10]. Linagliptin is a highly tissue-penetrative DPP-4 inhibitor. In Zucker diabetic fatty rats linagliptin augmented vascular relaxation [11]. In Dahlsensitive hypertensive rats linagliptin was found to improve vascular function and diabetic nephropathy, indicated by reduced albuminuria and renal mRNA levels of intercellular adhesion molecule-1 (ICAM-1), and in a rat model of type 1 diabetes it improved lymphocyte infiltration into the glomeruli $[12,13]$. However, similar analyses of the effects of DPP-4 inhibitors on vascular and endothelial function in humans with diabetes mellitus are lacking.

The aim of our study was to determine whether linagliptin improves renal vascular endothelium function in patients with type 2 diabetes in the early stage of their disease.

\section{Methods}

Study design This randomised, double-blind, parallel-group, investigator-initiated trial was conducted under the legal sponsorship of the Medical Faculty of Friedrich-Alexander University Erlangen-Nürnberg, Germany between October 2012 and December 2013. Participants were recruited from the University Outpatient Clinic, referring physicians and advertisements in local newspapers in the area of ErlangenNürnberg, Germany, and eligible individuals were enrolled consecutively. Written informed consent was obtained prior to study inclusion. Participants underwent a run-in/wash-out phase of 2 weeks if untreated (15\%) or 4 weeks if pre-treated with any blood-glucose-lowering agent $(85 \%)$. Thereafter, baseline measurement of renal endothelial function was performed and study participants were randomly assigned to receive either linagliptin $5 \mathrm{mg}$ or placebo for 4 weeks. Measurements of renal endothelial function were repeated at the end of the treatment phase. Patient disposition is given in Fig. 1. The local Pharmacy of the University Hospital Erlangen manufactured identical-appearing study medication. The study protocol was approved by the Local Ethics Committee (University of Erlangen-Nürnberg) and the study was conducted in accordance with the Declaration of Helsinki and the principles of 'good clinical practice' (GCP) guidelines. The study was registered at Clinical Trials.gov (registration no. NCT01835678).

The financial supporter Boehringer Ingelheim did not contribute to study conduction, data collection or interpretation of the data.

Study population Inclusion criteria were individuals with type 2 diabetes aged between 18 and 65 years. Main exclusion criteria were use of insulin, thiazolidinedione or DPP-4 inhibitor within the last 3 months or use of any other oral glucoselowering drug that could not be discontinued for the study period. Furthermore, patients with $\mathrm{HbA}_{1 \mathrm{c}}>10 \%(86 \mathrm{mmol} /$ $\mathrm{mol}$ ), urinary albumin to creatinine ratio (UACR) $>11.3 \mathrm{mg} /$ $\mathrm{mmol}(>100 \mathrm{mg} / \mathrm{g})$ creatinine, estimated glomerular filtration rate (eGFR) $<45 \mathrm{ml} \mathrm{min}^{-1} 1.73 \mathrm{~m}^{-2}$, and cardio- and cerebrovascular event within the previous 6 months were excluded. Female participants had to have a negative pregnancy test before and during the study period.

\section{Determination of renal haemodynamics and basal NO} activity Renal haemodynamics were assessed using the constant-infusion input-clearance technique with inulin (Inutest; Fresenius, Linz, Austria) and sodium $p$-aminohippurate (PAH) (Clinalfa, Basel, Switzerland) for measuring GFR and renal plasma flow (RPF), respectively, (www.crc-erlangen.de) $[14,15]$. In brief, after bolus infusion of inulin and PAH over $15 \mathrm{~min}$ and a subsequent constant infusion over $105 \mathrm{~min}$, a steady state between input and renal excretion of the tracer substances is reached (Fig. 2). Duplicate blood samples were collected for the assessment of RPF and GFR. Then, the competitive NOS inhibitor L-NMMA was administered intravenously as a bolus infusion ( $3 \mathrm{mg} / \mathrm{kg}$ over $5 \mathrm{~min}$ ) followed by constant infusion $(1.25 \mathrm{mg} / \mathrm{kg}$ over $25 \mathrm{~min})$, resulting in a total dose of L-NMMA of $4.25 \mathrm{mg} / \mathrm{kg}$ body weight. Again, a steady state was achieved and duplicate blood samples were collected for the assessment of RPF and GFR [3]. PAH was measured 
Fig. 1 Flow diagram of patient disposition

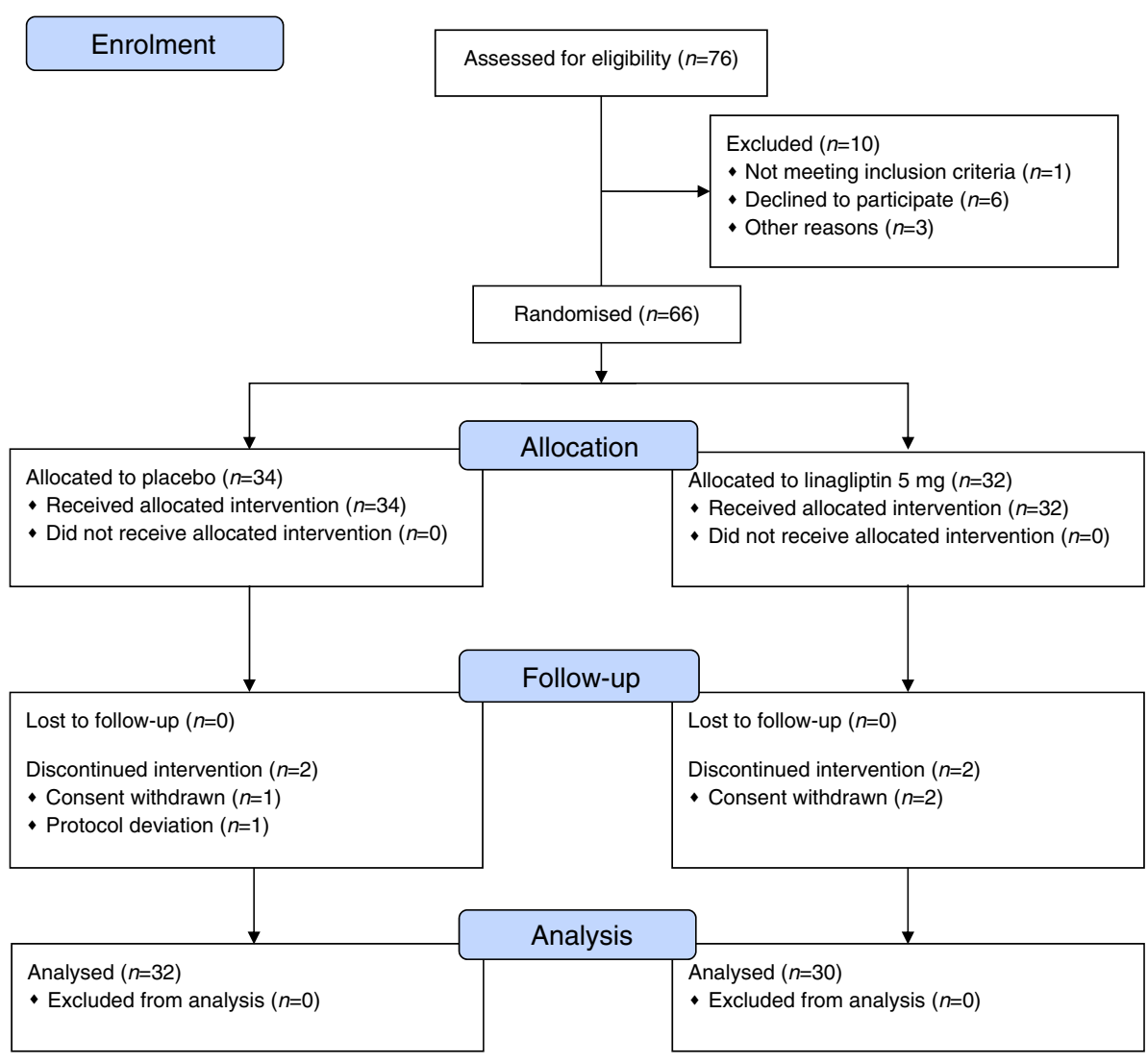

according to previously described methods [16]. Inulin was measured indirectly by converting inulin to fructose and subsequently measuring fructose by an enzymatic method (Boehringer Mannheim, Mannheim, Germany). Each blood sample was measured in duplicate with a coefficient variation of $<5 \%$.

\section{Calculation of intraglomerular haemodynamics} Intraglomerular pressure $\left(\mathrm{P}_{\text {glom }}\right)$ and resistances of the afferent $\left(\mathrm{R}_{\mathrm{A}}\right)$ and efferent $\left(\mathrm{R}_{\mathrm{E}}\right)$ arterioles were calculated according to the model originally established by Gomez [17], which has been discussed by Guidi et al [18] and repeatedly applied in previous studies [19, 20].

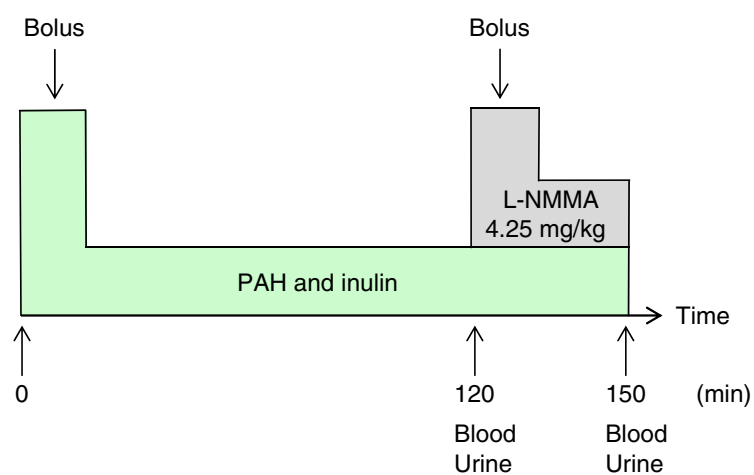

Fig. 2 Experimental protocol for constant-infusion input-clearance technique showing time points of blood and urine draws
Measurement of UACR Before the experimental protocol (constant-infusion input-clearance with $\mathrm{PAH}$ and inulin) was started, participants were advised to empty the bladder, and the urine was discarded. A constant infusion $(250 \mathrm{ml} / \mathrm{h})$ of sodium chloride was administered throughout the protocol. After $120 \mathrm{~min}$ of rest (basal urine), and again after $30 \mathrm{~min}$ (NOS inhibition with L-NMMA), participants were advised to urinate. All samples were processed centrally at the biochemistry laboratory of the University of Erlangen-Nürnberg according to established methods. In brief, the urinary albumin concentration was measured by a turbidimetric method (inter-assay CV $3.44 \%$ ) and the creatinine concentration in urine was measured photometrically by the Jaffé method (inter-assay CV 2.03\%). UACR was calculated by dividing urinary albumin concentration by urinary creatinine concentration.

Measurement of tubular markers Liver-type fatty acid binding protein (L-FABP), neutrophil gelatinase-associated lipocalin (NGAL), kidney injury molecule-1 (KIM-1) and tissue inhibitor of metalloproteinase-2 (TIMP-2) levels were determined using individual ELISAs (R\&D Systems Europe, Abingdon, UK).

Measurement of inflammatory markers High-sensitivity C-reactive protein (hs-CRP) was determined using a 
particle-enhanced nephelometric assay. Monocyte chemoattractant protein-1 (MCP-1) was determined using an ELISA (R\&D Systems Europe).

Measurement of serum NO Serum nitrite $\left(\mathrm{NO}_{2}{ }^{-}\right)$and nitrate $\left(\mathrm{NO}_{3}{ }^{-}\right)$concentrations, as an index of NO production/ oxidative stress, were determined using a two-option assay (R\&D Systems Europe).

Statistical analysis According to the statistical analysis plan the following steps of analysis were specified. The primary step was to compare renal endothelial function (basal NO activity) between the two randomised groups, assessed at the 4 weeks examination, after the 2-4 weeks of run-in/wash-out phase and an additional 4 weeks of treatment phase. Sample size calculation was based on data from prior studies in individuals with type 2 diabetes [5,21]. Secondary steps were to analyse all other variables at the 4 weeks examination. Finally changes from baseline to the 4 weeks examination were separately analysed in the linagliptin and placebo groups.

Normal distribution of data was confirmed by KolmogorovSmirnov tests before further analysis. Normally distributed data were compared by paired and unpaired Student's $t$ test and were expressed as mean $\pm \mathrm{SD}$. UACR data were not normally distributed; therefore the Mann-Whitney $U$ test and Wilcoxon rank sum test were used and results were expressed as median (interquartile range). Two-tailed values of $p<0.05$ were considered statistically significant. All analyses were performed using IBM SPSS Statistics for Windows, Version 21.0 (IBM, Armonk, NY, USA).

\section{Results}

Clinical characteristics Our study population (mean age 56.9 years, $\mathrm{HbA}_{1 \mathrm{c}} 6.89 \%$ [52 $\mathrm{mmol} / \mathrm{mol}$ ], blood pressure $132 / 79 \mathrm{mmHg}$ ) had a short duration of diabetes (4.5 years), normal renal function and albuminuria $<11.3 \mathrm{mg} / \mathrm{mmol}$ ( $<100 \mathrm{mg} / \mathrm{g}$ creatinine). At baseline (after the run-in/washout phase) no significant differences in clinical characteristics were documented between patients randomised to receive linagliptin and placebo treatment (Table 1). Also, no difference in previous glucose-lowering medication or current antihypertensive drugs and statins existed (data not shown).

After 4 weeks of treatment, fasting $(7.61 \pm 1.4$ vs 7.17 $\pm 1.7 \mathrm{mmol} / \mathrm{l}, p=0.072)$ and postprandial $(9.50 \pm 1.2 \mathrm{vs} 8.89$ $\pm 2.5 \mathrm{mmol} / \mathrm{l}, p=0.076)$ blood glucose and $\mathrm{HbA}_{1 \mathrm{c}}(6.98 \pm 0.7 \%$ $[53 \pm 7.7 \mathrm{mmol} / \mathrm{mol}]$ vs $6.86 \pm 0.8 \%[51 \pm 8.7 \mathrm{mmol} / \mathrm{mol}]$, $p=0.089$ ) were reduced (although not significantly) in the linagliptin group whereas no change was noted in the placebo group (fasting glucose $7.44 \pm 1.8 \mathrm{v} 7.67 \pm 1.8 \mathrm{mmol} / \mathrm{l}, p=0.218$; postprandial glucose $9.61 \pm 2.9$ vs $9.28 \pm 2.8 \mathrm{mmol} / 1$, $p=0.0225 ; \mathrm{HbA}_{1 \mathrm{c}} 6.79 \pm 0.8 \%[51 \pm 8.7 \mathrm{mmol} / \mathrm{mol}]$ vs 6.83 $\pm 0.9 \%[51 \pm 9.8 \mathrm{mmol} / \mathrm{mol}], p=0.559)$.
Table 1 Baseline clinical characteristics

\begin{tabular}{llll}
\hline Characteristic & Placebo group $(n=32)$ & Linagliptin group $(n=30)$ & $p$ value \\
\hline Age (years) & $57.2 \pm 8.8$ & $56.6 \pm 9.8$ & 0.779 \\
Sex (men/women) & $18 / 14$ & $21 / 9$ & 0.269 \\
Mean diabetes duration (years) & $5.1 \pm 3.0$ & $3.8 \pm 3.3$ & 0.112 \\
$\mathrm{HbA}_{1 \mathrm{c}}(\%)$ & $6.79 \pm 0.8$ & $6.98 \pm 0.7$ & 0.338 \\
$\mathrm{HbA}_{1 \mathrm{c}}(\mathrm{mmol} / \mathrm{l})$ & $51 \pm 8.7$ & $53 \pm 7.7$ & 0.338 \\
Glucose (mmol/l) $_{\text {Fasting }}$ & & & \\
Postprandial & $7.44 \pm 1.8$ & $7.61 \pm 1.4$ & 0.762 \\
RAS-modulating agents & $9.61 \pm 2.9$ & $9.50 \pm 1.2$ & 0.742 \\
Office blood pressure (mmHg) & $16(50)$ & $10(33.3)$ & 0.187 \\
Systolic & & & 0.504 \\
Diastolic & $131 \pm 12$ & $133 \pm 14$ & 0.402 \\
BMI (kg/m ${ }^{2}$ ) & $78 \pm 9$ & $80 \pm 9$ & 0.895 \\
Cholesterol-modulating agents & $29.8 \pm 4.8$ & $29.6 \pm 4.0$ & 0.912 \\
Lipids (mmol/l) & $5(15.6)$ & $5(16.7)$ & \\
Total cholesterol & & & 0.986 \\
LDL-cholesterol & $5.40 \pm 0.9$ & $5.40 \pm 0.9$ & 0.972 \\
HDL-cholesterol & $3.67 \pm 0.7$ & $3.67 \pm 0.7$ & 0.842 \\
Triacylglycerols & $1.22 \pm 0.2$ & $1.22 \pm 0.3$ & 0.830 \\
\hline
\end{tabular}

Data are means $\pm \mathrm{SD}, n$ or $n(\%)$

RAS, renin-angiotensin system 
Renal endothelial function The change in RPF due to L-NMMA was smaller after 4 weeks of treatment with linagliptin compared with placebo (irrespective of whether expressed in absolute [ $p=0.045$, Table 2$]$ or percentage values $[p=0.046$, Fig. 3]), indicating lower basal NO activity after treatment with linagliptin.

In accordance, when baseline was compared with treatment groups, the change in RPF due to L-NMMA was greater (though not statistically significantly) after placebo $(p=0.058)$, but remained unchanged after linagliptin treatment $(p=0.823$, Table 2).

Renal haemodynamics After 4 weeks of treatment, there was no difference in RPF and GFR between linagliptin and placebo groups (Table 2).

Comparing renal haemodynamics at baseline with those after 4 weeks of treatment, there was no difference in RPF and GFR between linagliptin and placebo groups, respectively (Table 2).

Intrarenal haemodynamics After 4 weeks of treatment with linagliptin compared with placebo, no significant differences in $P_{\text {glom }}, R_{A}, R_{E}$ or the ratio $R_{E} / R_{A}$ were observed (Table 2).

There were no significant differences in intrarenal haemodynamics after linagliptin treatment compared with baseline. In contrast, when comparing intrarenal haemodynamics at baseline with placebo treatment, a significant reduction in $R_{A}$, and hence an increase in $R_{E} / R_{A}$, was observed, whereas there was no change in $\mathrm{P}_{\text {glom }}$ and $\mathrm{R}_{\mathrm{E}}$ (Table 2).

Response of UACR due to L-NMMA After 4 weeks of treatment, there was no difference in the response of UACR due to L-NMMA between linagliptin and placebo (median [interquartile range]: $59.5[11.7-160] \%)$ vs $20.4[-8.5$ to $139] \%, p=0.233)$.

At baseline $(p=0.043)$ and after 4 weeks of placebo treatment $(p=0.001)$ there was a significant increase in UACR in response to L-NMMA. This increase in response was enhanced after 4 weeks of placebo compared with baseline ( $p=0.059$ ), pointing toward an upregulation of NO activity in the ('untreated') placebo group, whereas UACR in response to L-NMMA did not change in the linagliptin group $(p=0.276)$ (Fig. 4).

Tubular markers KIM-1 levels increased non-significantly after linagliptin treatment compared with placebo treatment $(p=0.067)$, whereas no changes in NGAL, L-FABP or TIMP-2 were noted.

Comparing tubular markers before (baseline) and after placebo treatment, there was a significant increase in TIMP-2 levels after 4 weeks of treatment $(p=0.048)$ and a nonsignificant increase in KIM-1 levels $(p=0.057)$. No significant differences were observed between baseline and 4 weeks of linagliptin treatment (Table 3).

Inflammatory markers Comparing 4 weeks of treatment with linagliptin vs placebo, hs-CRP ( $p=0.019$, Fig. 5), but not MCP-1 (412 \pm 116 vs $452 \pm 145 \mathrm{ng} / \mathrm{ml}, p=0.260)$, was significantly lower.

No significant differences in hs-CRP and MCP-1 levels (447 \pm 150 vs $452 \pm 145 \mathrm{ng} / \mathrm{ml}, p=0.642$ ) were observed between baseline and 4 weeks of treatment with placebo. In contrast, after linagliptin treatment both hs-CRP ( $p=0.026$, Fig. 5) and MCP-1 (412 \pm 116 vs $440 \pm 139 \mathrm{ng} / \mathrm{ml}, p=0.022)$ were significantly reduced compared with levels at baseline.

Table 2 Renal and intrarenal haemodynamics

\begin{tabular}{|c|c|c|c|c|c|c|c|}
\hline \multirow[t]{2}{*}{ Variable } & \multicolumn{3}{|c|}{ Placebo $(n=32)$} & \multicolumn{3}{|c|}{ Linagliptin $(n=30)$} & \multirow{2}{*}{$\begin{array}{l}\text { Placebo vs linagliptin } \\
p \text { value }^{\mathrm{b}}\end{array}$} \\
\hline & Baseline & 4 weeks & $p$ value $^{\mathrm{a}}$ & Baseline & 4 weeks & $p$ value $^{\mathrm{a}}$ & \\
\hline \multicolumn{8}{|l|}{$\mathrm{RPF}$ (ml/min) } \\
\hline Before L-NMMA & $614 \pm 87$ & $630 \pm 90$ & 0.266 & $600 \pm 100$ & $607 \pm 102$ & 0.643 & 0.355 \\
\hline After L-NMMA & $563 \pm 82$ & $565 \pm 93$ & 0.887 & $551 \pm 102$ & $560 \pm 96$ & 0.548 & 0.856 \\
\hline$\triangle \mathrm{RPF}$ & $-51.7 \pm 28$ & $-65.1 \pm 36$ & 0.058 & $-48.8 \pm 44$ & $-46.8 \pm 34$ & 0.823 & 0.045 \\
\hline GFR (ml/min) & $141 \pm 15$ & $143 \pm 16$ & 0.454 & $140 \pm 14$ & $140 \pm 14$ & 0.946 & 0.494 \\
\hline $\mathrm{P}_{\text {glom }}(\mathrm{mmHg})$ & $67.7 \pm 3.7$ & $68.3 \pm 4.1$ & 0.521 & $67.8 \pm 3.8$ & $67.9 \pm 3.7$ & 0.819 & 0.743 \\
\hline $\mathrm{R}_{\mathrm{E}}\left(\right.$ dyn s cm $\left.{ }^{-5}\right)$ & $2615 \pm 552$ & $2555 \pm 493$ & 0.458 & $2633 \pm 355$ & $2616 \pm 395$ & 0.796 & 0.593 \\
\hline $\mathrm{R}_{\mathrm{A}}\left(\right.$ dyn s cm$\left.{ }^{-5}\right)$ & $2149 \pm 836$ & $1703 \pm 662$ & 0.004 & $2210 \pm 1987$ & $2103 \pm 1120$ & 0.553 & 0.089 \\
\hline $\mathrm{R}_{\mathrm{E}} / \mathrm{R}_{\mathrm{A}}$ & $1.40 \pm 0.6$ & $1.79 \pm 1.0$ & 0.016 & $1.43 \pm 0.7$ & $1.44 \pm 0.6$ & 0.914 & 0.101 \\
\hline
\end{tabular}

Data are means \pm SD

${ }^{\text {a }}$ Comparisons made between baseline and 4 weeks of treatment

${ }^{\mathrm{b}}$ Comparisons made after 4 weeks of treatment 


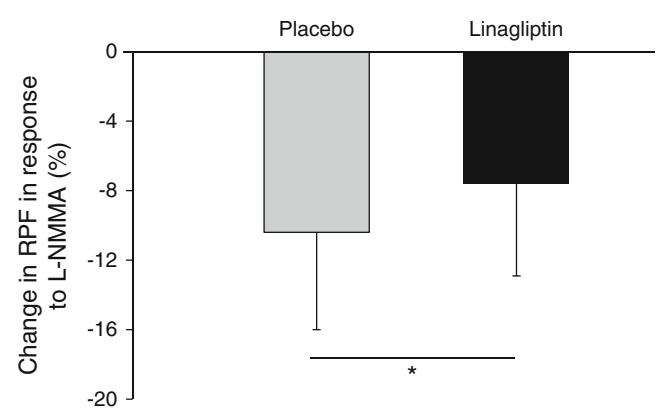

Fig. 3 Change in RPF in response to L-NMMA after 4 weeks of treatment with placebo or linagliptin. Data are shown as mean $\pm \mathrm{SD} ; * p<0.05$

Serum NO concentration Baseline serum $\mathrm{NO}_{2}{ }^{-}$and $\mathrm{NO}_{3}{ }^{-}$ concentration did not differ between the placebo and linagliptin groups $(p=0.117)$. However, after 4 weeks of treatment serum $\mathrm{NO}_{2}{ }^{-}$and $\mathrm{NO}_{3}{ }^{-}$concentrations increased in the placebo group but decreased in the linagliptin group, resulting in a significant difference (5.14 $\pm 14 \mathrm{mmol} / \mathrm{l}$ vs $-4.16 \pm 11 \mathrm{mmol} / \mathrm{l}, p=0.042$ ).

\section{Discussion}

The principal finding of our study is that the change in RPF due to L-NMMA, indicative of basal NO activity, was smaller after 4 weeks of treatment with linagliptin compared with placebo. This finding has to be interpreted in consideration of the fact that the final examination took place after 2-4 weeks of run-in/wash-out phase (baseline examination) and 4 weeks of treatment with either placebo or linagliptin. Interestingly, in the placebo group basal $\mathrm{NO}$ activity showed a non-significant increase $(p=0.058)$, which was not at all the case in the linagliptin group. This suggests that the increase in NO production in type 2 diabetes, such as that observed in the participants off glucose-lowering therapy for 8 weeks in the placebo group, is prevented by linagliptin treatment.

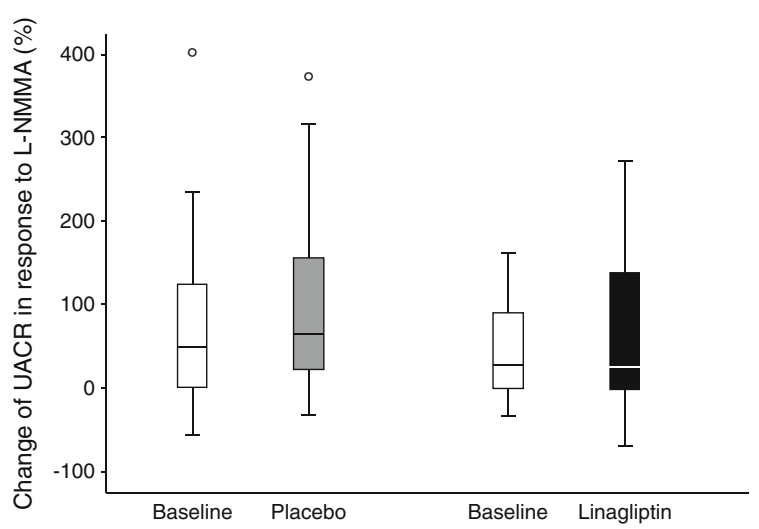

Fig. 4 Change in UACR in response to L-NMMA at baseline and after placebo or linagliptin treatment. Data are shown as median, interquartile range and outliers (open circles)
This result is in line with findings from previous animal experiments and histopathological human studies. In a rat model of streptozotocin (STZ)-induced diabetes, plasma and urinary excretion levels of stable products of $\mathrm{NO}$ oxidation were considerably higher than in control rats, suggesting an increased NO synthesis [22]. Accordingly, in humans with diabetes, increased $\mathrm{NO}$ synthesis assessed by serum $\mathrm{NO}_{2}{ }^{-}$ and $\mathrm{NO}_{3}{ }^{-}$concentrations was documented [23]. Moreover, increased renal expression of endothelial NOS and production of inducible NOS has been observed even in the very early stages of the disease, at 1 week after STZ induction of diabetes in rats [24]. Again, eNOS expression was increased and related to vascular lesions and the degree of proteinuria in renal biopsies from humans with diabetic nephropathy [25]. The increased $\mathrm{NO}$ expression and activity is commonly considered to be reactive and compensatory to the increased oxidative stress caused by increased blood glucose concentrations (glucotoxicity) [26, 27]. Indeed, in individuals with type 2 diabetes vitamin $\mathrm{C}$ infusion augmented endotheliumdependent vasodilatation of the forearm blood flow and of the renal vasculature $[28,29]$. Moreover, it was shown in individuals with type 2 diabetes that poor glycaemic control is related to an increased $\mathrm{NO}$ activity of the renal circulation [27] and that fluctuating glucose concentrations augment oxidative stress [30]. In accordance, treatment with gliptins, to blunt glycaemic fluctuations, was associated with reduced oxidative stress [13, 31]. Thus, our main finding of a lower basal $\mathrm{NO}$ activity in the group treated for 4 weeks with linagliptin points to a lesser degree of oxidative stress and lesser compensatory increased $\mathrm{NO}$ activity than in the placebo group.

These notions are supported by additional analyses of collected samples for serum $\mathrm{NO}_{2}{ }^{-}$and $\mathrm{NO}_{3}{ }^{-}$concentrations as an index of NO production/oxidative stress. Starting from comparable baseline values, serum $\mathrm{NO}_{2}{ }^{-}$and $\mathrm{NO}_{3}{ }^{-}$concentrations increased in the placebo group but decreased in the linagliptin group, resulting in a significant difference after 4 weeks of treatment. This result strengthens our observation of a beneficial effect on renal endothelial function assessed by change in RPF due to L-NMMA with linagliptin treatment. Notably, the measured values are in line with those from previous publications about individuals with diabetes, which also indicated an increased NO production and/or action due to chronic hyperglycaemia, leading to alterations in intrarenal haemodynamics [32].

Further evidence for this concept of an increased $\mathrm{NO}$ availability in early type 2 diabetes is supported by our results concerning secondary-objective variables. Previously we have shown that NOS inhibition (by L-NMMA) provokes albuminuria, unrelated to changes in blood pressure [3]. Our finding, in this study, that the increase in UACR due to L-NMMA was enhanced in the placebo group compared with baseline, points towards an upregulation of $\mathrm{NO}$ activity in the 'untreated' placebo group. Further, our finding that there was 
Table 3 Tubular markers

\begin{tabular}{|c|c|c|c|c|c|c|c|}
\hline \multirow[t]{2}{*}{ Variable } & \multicolumn{3}{|c|}{ Placebo $(n=32)$} & \multicolumn{3}{|c|}{ Linagliptin $(n=30)$} & \multirow{2}{*}{$\begin{array}{l}\text { Placebo vs Linagliptin } \\
p \text { value }^{\mathrm{b}}\end{array}$} \\
\hline & Baseline & 4 weeks & $p$ value $^{\mathrm{a}}$ & Baseline & 4 weeks & $p$ value ${ }^{\mathrm{a}}$ & \\
\hline \multicolumn{8}{|l|}{ Plasma } \\
\hline L-FABP (ng/ml) & $82.5 \pm 26$ & $83.4 \pm 33$ & 0.840 & $67.6 \pm 24$ & $67.4 \pm 26$ & 0.960 & 0.063 \\
\hline NGAL (ng/ml) & $32.2 \pm 19$ & $32.8 \pm 19$ & 0.653 & $30.2 \pm 16$ & $31.0 \pm 17$ & 0.672 & 0.678 \\
\hline \multicolumn{8}{|l|}{ First morning urine } \\
\hline NGAL (ng/ml) & $5.37 \pm 6.6$ & $7.04 \pm 9.6$ & 0.204 & $7.16 \pm 6.8$ & $6.03 \pm 5.8$ & 0.429 & 0.637 \\
\hline KIM-1 (ng/ml) & $0.92 \pm 0.6$ & $1.07 \pm 0.7$ & 0.057 & $0.96 \pm 0.8$ & $0.76 \pm 0.5$ & 0.157 & 0.067 \\
\hline TIMP-2 (ng/ml) & $2.97 \pm 2.8$ & $4.28 \pm 3.7$ & 0.048 & $3.26 \pm 2.6$ & $3.36 \pm 1.8$ & 0.856 & 0.239 \\
\hline
\end{tabular}

Data are means + SD

${ }^{a}$ Comparisons made between baseline and 4 weeks of treatment

${ }^{\mathrm{b}}$ Comparisons made after 4 weeks of treatment

a significant reduction in $R_{A}$, and hence an increase in $R_{E} / R_{A}$, after placebo treatment is also supportive. It has been shown that the superoxide anion, indicative of oxidative stress, leads to vasoconstriction of the afferent arteriole [33]. By immunohistochemistry, endothelial NOS but not inducible NOS, staining was observed in the endothelium of preglomerular vessels (afferent arterioles) of diabetic rats as opposed to controls [34]. Moreover, after diabetes was induced by STZ in rats, the diameter of afferent arterioles (but not of efferent arterioles) and levels of urinary $\mathrm{NO}_{2}{ }^{-} \mathrm{NO}_{3}{ }^{-}$were increased, both returning to baseline levels after treatment with L-NAME [35]. These results support the notion that increased NO availability due to greater abundance of endothelial NOS provokes afferent arteriolar dilatation (with consequent glomerular hyperfiltration) in the early stage of diabetic nephropathy $[6,35]$. This vasodilatory response of preglomerular vessels is obviously prevented by linagliptin, but not by placebo.

Support for the beneficial impact of linagliptin on early renal changes also comes from our finding that tubular markers remained unchanged in the linagliptin group whereas there was a significant increase in TIMP-2 levels and a nonsignificant increase in KIM-1 levels after placebo treatment

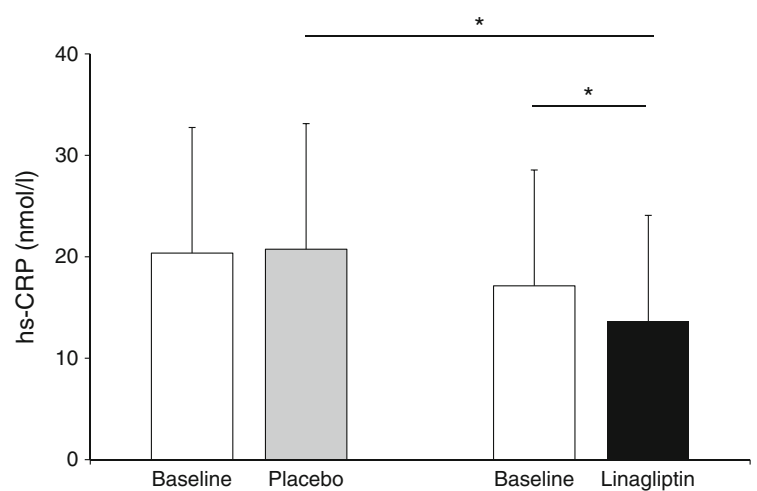

Fig. 5 hs-CRP at baseline and after placebo or linagliptin treatment. Data are shown as means $\pm \mathrm{SD} ;{ }^{*} p<0.05$ compared with baseline. In a case-control study using the Multi-Ethnic Study of Atherosclerosis, urinary KIM-1 concentration was associated with future risk of kidney disease (defined as incident chronic kidney disease stage 3 and/or rapid kidney function decrease) independent of albuminuria [36]. In two community-based studies, lower insulin sensitivity was found to be associated with increased urinary KIM-1 levels, even after adjustment for confounders including eGFR and UACR [37]. In individuals with type 1 diabetes followedup for 5-15 years, after adjustment for baseline UACR, eGFR and $\mathrm{HbA}_{1 \mathrm{c}}$, baseline serum KIM-1 levels were predictive of decrease in eGFR and risk of ESRD [38].

Our study also revealed that hs-CRP and MCP-1 levels were significantly reduced after linagliptin treatment compared with levels at baseline, indicative of a reduced inflammatory process (i.e. vascular injury), which has been reported in the early stages of diabetic vascular damage. It is worth noting that any influence of acute infection was ruled out, since hs-CRP values above $47.6 \mathrm{nmol} / \mathrm{l}(5 \mathrm{mg} / \mathrm{l})$ were excluded. In an animal model (obese, hypertensive and insulinresistant mice fed with a western diet), elevated MCP-1 levels were documented, and these were diminished after DPP-4 inhibition [39]. Moreover, in Zucker diabetic fatty rats, vascular expression of the gene encoding MCP-1 was attenuated by the highly tissue-penetrating linagliptin even when compared with sitagliptin [11]. In individuals in whom diabetes was uncontrolled and who had coronary artery disease, additional DPP-4 inhibition was found to improve endothelial function (assessed by reactive hyperaemia peripheral arterial tonometry) and decrease hs-CRP, in contrast to the control group. Moreover, linear regression analysis revealed a significant correlation between changes in endothelial function and hs-CRP but not $\mathrm{HbA}_{1 \mathrm{c}}$ [40]. In an accompanying editorial it was questioned whether oxidative stress, known to be increased in diabetes, may have impact on these results [41]. 
A major limitation of our study is that we did not assess oxidative stress, although not all of its markers reflect the oxidative stress in the renal parenchyma. Estimation of intrarenal haemodynamics was based on a calculation model and was not directly assessed. Its reliability rests upon some assumptions. Therefore, we are aware that the model by Gomez, as with any other model using raw variables and constants, does not provide any information that cannot be gained from the raw variables. However, this technique can reliably be used in patients without kidney disease and with maintained renal function, particularly if intra-individual comparisons are to be analysed and if data are obtained twice within a short period of time. Our findings cannot be extrapolated to type 2 diabetes in general, since our participants were at an early stage of diabetes. The study treatment period was 4 weeks preceded by 4 weeks off treatment in the majority of participants (i.e. 8 weeks off active therapy in the placebo group). Interestingly, most changes in our biomarkers were noted in the placebo group and not in the linagliptin group. We therefore interpret our data more as preventive effects of linagliptin attenuating the natural course of the disease (as observed in the placebo group).

In conclusion, our data suggest that treatment with the DPP-4 inhibitor linagliptin for 4 weeks prevented the impairment of renal endothelial function due to hyperglycaemia in type 2 diabetes.

Acknowledgements We gratefully acknowledge the expert technical assistance of O. Alter, D. Bader-Schmieder, I. Fleischmann, K. Fröhlich-Endreß, U. Heinritz, S. Muck, S. Pejkovic and L. Waldmann (all from Friedrich-Alexander-University ErlangenNürnberg (FAU), Erlangen, Germany). The present work was performed in fulfilment of the requirements for obtaining the doctoral title 'Dr. med.' (MK).

Part of the work was presented at the 25th European Meeting on Hypertension and Cardiovascular Protection, Milan, 2015.

Funding The study was an investigator-initiated clinical trial funded by Boehringer Ingelheim to the University Hospital, Erlangen, Germany.

Duality of interest RES has received speaker fees and consultancy and advisory board fees from Boehringer Ingelheim. PB has received research support from Boehringer Ingelheim. All other authors declare that there is no duality of interest associated with their contribution to this manuscript.

Contribution statement $\mathrm{CO}$ contributed to the conception and design of the study, researched and analysed data and wrote the manuscript. IK, MK and SF researched data. CW and PB analysed data. RES contributed to the conception and design of the study, analysed data and wrote the manuscript. All authors revised the manuscript for important intellectual content and gave final approval of the current version to be published. RES is the guarantor of this work and, as such, had full access to all the data in the study and takes responsibility for the integrity of the data and the accuracy of the data analysis.

\section{References}

1. Redon J, Morales-Olivas F, Galgo A et al (2006) Urinary albumin excretion and glomerular filtration rate across the spectrum of glucose abnormalities in essential hypertension. J Am Soc Nephrol 17: S236-S245

2. Ruilope L, Izzo J, Haller H et al (2010) Prevention of microalbuminuria in patients with type 2 diabetes: what do we know? J Clin Hypertens 12:422-430

3. Ott C, Schneider MP, Delles C, Schlaich MP, Schmieder RE (2011) Reduction in basal nitric oxide activity causes albuminuria. Diabetes 60:572-576

4. Ott C, Schlaich MP, Schmidt BM, Titze SI, Schaufele T, Schmieder RE (2008) Rosuvastatin improves basal nitric oxide activity of the renal vasculature in patients with hypercholesterolemia. Atherosclerosis 196:704-711

5. Ritt M, Ott C, Raff U et al (2009) Renal vascular endothelial function in hypertensive patients with type 2 diabetes mellitus. Am J Kidney Dis 53:281-289

6. Veelken R, Hilgers KF, Hartner A, Haas A, Bohmer KP, Sterzel RB (2000) Nitric oxide synthase isoforms and glomerular hyperfiltration in early diabetic nephropathy. J Am Soc Nephrol 11:71-79

7. Schlaich MP, Schmitt D, Ott C, Schmidt BM, Schmieder RE (2008) Basal nitric oxide synthase activity is a major determinant of glomerular haemodynamics in humans. J Hypertens 26:110-116

8. Holst JJ, Deacon CF (2005) Glucagon-like peptide-1 mediates the therapeutic actions of DPP-IV inhibitors. Diabetologia 48:612-615

9. Ozyazgan S, Kutluata N, Afsar S, Ozdas SB, Akkan AG (2005) Effect of glucagon-like peptide-1(7-36) and exendin-4 on the vascular reactivity in streptozotocin/nicotinamide-induced diabetic rats. Pharmacology 74:119-126

10. Shah Z, Pineda C, Kampfrath T et al (2011) Acute DPP-4 inhibition modulates vascular tone through GLP-1 independent pathways. Vasc Pharmacol 55:2-9

11. Takai S, Sakonjo H, Jin D (2014) Significance of vascular dipeptidyl peptidase-4 inhibition on vascular protection in Zucker diabetic fatty rats. J Pharmacol Sci 125:386-393

12. Koibuchi N, Hasegawa Y, Katayama T et al (2014) DPP-4 inhibitor linagliptin ameliorates cardiovascular injury in salt-sensitive hypertensive rats independently of blood glucose and blood pressure. Cardiovasc Diabetol 13:157

13. Nakashima S, Matsui T, Takeuchi M, Yamagishi SI (2014) Linagliptin blocks renal damage in type 1 diabetic rats by suppressing advanced glycation end products-receptor axis. Horm Metab Res 46:717-721

14. Schmieder RE, Gatzka C, Schobel H, Schachinger H, Weihprecht H (1994) Renal hemodynamic response to stress is influenced by ACE-inhibitors. Clin Nephrol 42:381-388

15. Delles C, Klingbeil AU, Schneider MP, Handrock R, Schaufele T, Schmieder RE (2004) The role of nitric oxide in the regulation of glomerular haemodynamics in humans. Nephrol Dial Transplant 19:1392-1397

16. Smith HW, Finkelstein N, Aliminosa L, Crawford B, Graber M (1945) The renal clearances of substituted hippuric acid derivatives and other aromatic acids in dog and man. J Clin Invest 24:388-404

17. Gomez DM (1951) Evaluation of renal resistances, with special reference to changes in essential hypertension. J Clin Invest 30: $1143-1155$

18. Guidi E, Cozzi MG, Minetti EE, Civati G, Busnach G, Brando B (2001) Effect of familial hypertension on glomerular hemodynamics and tubulo-glomerular feedback after uninephrectomy. Am J Hypertens 14:121-128

19. Ott C, Ritt M, Titze SI, Schaufele T, Schmieder RE (2009) Rosuvastatin does not affect intrarenal hemodynamics in patients with hypercholesterolemia. J Nephrol 22:675-681 
20. Ott C, Schneider MP, Raff U et al (2013) Effects of manidipine vs. amlodipine on intrarenal haemodynamics in patients with arterial hypertension. Br J Clin Pharmacol 75:129-135

21. Schmieder RE, Delles C, Mimran A, Fauvel JP, Ruilope LM (2007) Impact of telmisartan versus ramipril on renal endothelial function in patients with hypertension and type 2 diabetes. Diabetes Care 30: 1351-1356

22. Bank N, Aynedjian HS (1993) Role of EDRF (nitric oxide) in diabetic renal hyperfiltration. Kidney Int 43:1306-1312

23. Chiarelli F, Cipollone F, Romano F et al (2000) Increased circulating nitric oxide in young patients with type 1 diabetes and persistent microalbuminuria: relation to glomerular hyperfiltration. Diabetes 49:1258-1263

24. Choi KC, Kim NH, An MR, Kang DG, Kim SW, Lee J (1997) Alterations of intrarenal renin-angiotensin and nitric oxide systems in streptozotocin-induced diabetic rats. Kidney Int Suppl 60:S23S27

25. Hohenstein B, Hugo CP, Hausknecht B, Boehmer KP, Riess RH, Schmieder RE (2008) Analysis of NO-synthase expression and clinical risk factors in human diabetic nephropathy. Nephrol Dial Transplant 23:1346-1354

26. Satoh M, Fujimoto S, Haruna Y et al (2005) NAD(P)H oxidase and uncoupled nitric oxide synthase are major sources of glomerular superoxide in rats with experimental diabetic nephropathy. Am J Physiol Renal Physiol 288:F1144-F1152

27. Schneider MP, Ott C, Schmidt S, Kistner I, Friedrich S, Schmieder RE (2013) Poor glycemic control is related to increased nitric oxide activity within the renal circulation of patients with type 2 diabetes. Diabetes Care 36:4071-4075

28. Delles C, Schneider MP, Oehmer S, Fleischmann I, Fleischmann EF, Schmieder RE (2004) Increased response of renal perfusion to the antioxidant vitamin $\mathrm{C}$ in type 2 diabetes. Nephrol Dial Transplant 19:2513-2518

29. Ting HH, Timimi FK, Boles KS, Creager SJ, Ganz P, Creager MA (1996) Vitamin C improves endothelium-dependent vasodilation in patients with non-insulin-dependent diabetes mellitus. J Clin Invest 97:22-28

30. Monnier L, Mas E, Ginet $\mathrm{C}$ et al (2006) Activation of oxidative stress by acute glucose fluctuations compared with sustained chronic hyperglycemia in patients with type 2 diabetes. JAMA 295:1681-1687
31. Rizzo MR, Barbieri M, Marfella R, Paolisso G (2012) Reduction of oxidative stress and inflammation by blunting daily acute glucose fluctuations in patients with type 2 diabetes: role of dipeptidyl peptidase-IV inhibition. Diabetes Care 35:2076-2082

32. Savino A, Pelliccia P, Schiavone $C$ et al (2006) Serum and urinary nitrites and nitrates and Doppler sonography in children with diabetes. Diabetes Care 29:2676-2681

33. Schnackenberg CG, Welch WJ, Wilcox CS (2000) TP receptormediated vasoconstriction in microperfused afferent arterioles: roles of $\mathrm{O}_{2}{ }^{-}$and NO. Am J Physiol Renal Physiol 279:F302-F308

34. Veelken R, Vogel EM, Hilgers K et al (2008) Autonomic renal denervation ameliorates experimental glomerulonephritis. J Am Soc Nephrol 19:1371-1378

35. Sugimoto H, Shikata K, Matsuda M et al (1998) Increased expression of endothelial cell nitric oxide synthase (ecNOS) in afferent and glomerular endothelial cells is involved in glomerular hyperfiltration of diabetic nephropathy. Diabetologia 41:14261434

36. Peralta CA, Katz R, Bonventre JV et al (2012) Associations of urinary levels of kidney injury molecule 1 (KIM-1) and neutrophil gelatinaseassociated lipocalin (NGAL) with kidney function decline in the Multi-Ethnic Study of Atherosclerosis (MESA). Am J Kidney Dis 60:904-911

37. Carlsson AC, Calamia M, Riserus U et al (2014) Kidney injury molecule (KIM)-1 is associated with insulin resistance: results from two community-based studies of elderly individuals. Diabetes Res Clin Pract 103:516-521

38. Sabbisetti VS, Waikar SS, Antoine DJ et al (2014) Blood kidney injury molecule- 1 is a biomarker of acute and chronic kidney injury and predicts progression to ESRD in type I diabetes. J Am Soc Nephrol 25:2177-2186

39. Nistala R, Habibi J, Lastra G et al (2014) Prevention of obesityinduced renal injury in male mice by DPP4 inhibition. Endocrinology 155:2266-2276

40. Matsubara J, Sugiyama S, Akiyama E et al (2013) Dipeptidyl peptidase-4 inhibitor, sitagliptin, improves endothelial dysfunction in association with its anti-inflammatory effects in patients with coronary artery disease and uncontrolled diabetes. Circ J 77: $1337-1344$

41. Satoh K (2013) Dipeptidyl peptidase-4 inhibitors-emerging player for vascular protection. Circ J 77:1156-1157 